Article

\title{
Functional Genomics of the Aeromonas salmonicida Lipopolysaccharide O-Antigen and A-Layer from Typical and Atypical Strains
}

Susana Merino $^{1, *}$, Elena de Mendoza ${ }^{1}$, Rocío Canals ${ }^{2}$ and Juan M. Tomás ${ }^{1}$

1 Department of Microbiology, Faculty of Biology, University of Barcelona, Diagonal 643, Barcelona 08071, Spain; E-Mails: elenademendoza@hotmail.com (E.M.); jtomas@ub.edu (J.M.T.)

2 Institute of Integrative Biology, University of Liverpool, Crown Street, Liverpool L69 7ZB, UK; E-Mail: rcanals@gmail.com

* Author to whom correspondence should be addressed. E-mail: smerino@ub.edu; Tel.: +34-93-4021708; Fax: +34-93-4039047.

Academic Editor: Antonio Molinaro

Received: 14 April 2015 / Accepted: 27 April 2015 / Published: 15 June 2015

\begin{abstract}
The A. salmonicida A450 LPS O-antigen, encoded by the $w b_{\text {salmo }}$ gene cluster, is exported through an ABC-2 transporter-dependent pathway. It represents the first example of an O-antigen LPS polysaccharide with three different monosaccharides in their repeating unit assembled by this pathway. Until now, only repeating units with one or two different monosaccharides have been described. Functional genomic analysis of this $w b$ salmo region is mostly in agreement with the LPS O-antigen structure of acetylated L-rhamnose (Rha), D-glucose (Glc), and 2-amino-2-deoxy-D-mannose (ManN). Between genes of the $w b_{\text {salmo }}$ we found the genes responsible for the biosynthesis and assembly of the S-layer (named A-layer in these strains). Through comparative genomic analysis and in-frame deletions of some of the genes, we concluded that all the A. salmonicida typical and atypical strains, other than A. salmonicida subsp. pectinolytica strains, shared the same $w b_{\text {salmo }}$ and presence of A-layer. A. salmonicida subsp. pectinolytica strains lack $w b_{\text {salmo }}$ and A-layer, two major virulence factors, and this could be the reason they are the only ones not found as fish pathogens.
\end{abstract}

Keywords: Aeromonas salmonicida; subspecies; genomics; proteomics; lipopolysaccharide O-antigen; A-surface layer 


\section{Introduction}

Currently, there are five accepted subspecies of Aeromonas salmonicida: A. salmonicida subsp. salmonicida, masoucida, achromogenes, pectinolytica and smithia [1]. Aeromonas salmonicida subsp. salmonicida is the etiological agent producing the systemic disease named furunculosis, being then an important fish pathogen [2]. This pathogen has been subjected to considerable investigation due to its importance in the farmed fish industry. Its major virulence factor is an S-layer (named A-layer), which principally consists of a unique two-dimensional crystalline tetragonal protein (A-protein with a molecular weight of $49 \mathrm{kDa}$ ) array [3], which is tethered to the cell by the lipopolysaccharide (LPS) [4].

Immunolabeling studies have been able to show that the A-layer appears to cover most of the surface of the virulent $A$. salmonicida [5], nevertheless some LPS molecules are still surface exposed [6]. Both LPS O-antigen and the A-layer are required to fully protect this bacterium from serum killing [7]. Although the A-layer is not completely necessary for the bacterium's resistance to serum killing, it is an important barrier against opsonophagocytosis [8].

In Gram-negative bacteria, the LPS are large amphiphilic molecules consisting of a hydrophilic polysaccharide part, and a covalently bound hydrophobic and highly conserved lipid component, termed lipid A (the bioactive endotoxin subunit). The polysaccharide part can be conceptually divided into two sub-domains: one more internal and conserved, the core region, and one more external and highly variable, the $\mathrm{O}$-specific chain, named also $\mathrm{O}$-antigen for its immunogenic properties. These three regions have been differentiated and formally classified by their chemical structure, degree of conservation, biosynthetic pathways and genetic determination (see general review, [9]).

Some studies have chemically characterized structures of the O-antigen polysaccharide and the core oligosaccharide regions of the LPS from A. salmonicida strain SJ-15 [10,11]. More recent studies describe the structural elucidation of the O-antigen LPS of the A. salmonicida subsp. salmonicida from strains A449 and 80204-1 [12], and their core oligosaccharide region [13]. We studied the functional genetics of the O-antigen of the LPS from A. salmonicida subsp. salmonicida strain A450, whose chemical structure is similar to the previously described for other strains [12]. Furthermore, we found genes encoding for the production and export/assembly of the A-layer characteristic from A. salmonicida subsp. salmonicida strains, between the biosynthetic genes for the LPS O-antigen

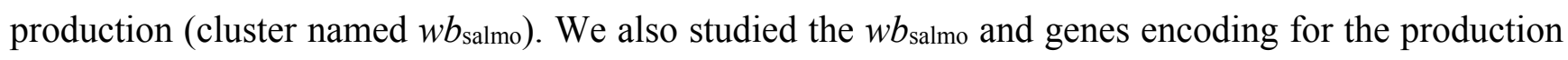
and export/assembly of the A-layer in different strains of subspecies masoucida, achromogenes, pectinolytica and smithia.

\section{Results}

LPS was extracted from enzymatically digested A. salmonicida A450 cells by the Westphal procedure [14] and the O-polysaccharide isolated after mild acid degradation. Sugar analysis by gas-liquid chromatography (GLC) of resultant monosaccharides as alditol acetates and (S)-octyl glycosides revealed that it was composed of L-rhamnose (Rha), D-glucose (Glc), and 2-amino-2-deoxy-D-mannose $(\mathrm{ManN})$ in the approximate molar ratio of 1:0.95:0.9. The methylation analysis of the $O$-polysaccharide revealed the presence of 2,3-di- $O$-methylrhamnose, 2- $O$-methylrhamnose, 2-deoxy-4,6-di- $O$-methyl-2- 
( $\mathrm{N}$-methylacetamido) mannose and 2,3,4,6-tetra- $\mathrm{O}$-methylglucose (Table 1 ), suggesting that the O-antigen polysaccharide contained 3,4-substituted Rha, 3-substituted ManNAc and terminal Glc.

Table 1. A. salmonicida A450 O-antigen LPS methylation analysis.

\begin{tabular}{ccc}
\hline Sugar Linkage & $\mathbf{R t}_{\mathbf{G M}}{ }^{\mathbf{a}}(\mathbf{m i n})$ & Relative Molar Ratios $^{\mathbf{b}}$ \\
\hline 4-Substituted Rha & 5.19 & 0.07 \\
Terminal Glc & 6.18 & 1.00 \\
3,4-Substituted Rha & 7.03 & 0.85 \\
3-Substituted ManNAc & 34.81 & 0.60 \\
\hline
\end{tabular}

${ }^{\text {a }}$ Retention time of the derived alditol acetate derivative adjusted to that of 1,5-di-O-acetyl-2,3,4,6-tetra-Omethylglucitol-1-d. ${ }^{\mathrm{b}}$ Total ion count based on the detector response.

The high-resolution electrospray ionization mass spectrum results obtained were consistent with those of compositional and methylation analyses. We found the presence of the fragment ion at $m / z 392.5$ suggesting that HexNAc was attached to RhaOAc, and a fragment ion at $\mathrm{m} / \mathrm{z} 554.5$ was consistent with the consecutive addition of Hex $(+162)$. Additional ions $(\mathrm{m} / \mathrm{z} 757.5,946.5$ and 1108.5) corresponded to the consecutive addition of sugar residues HexNAc, RhaOAc and Hex, respectively. From these initial studies, we concluded that the A. salmonicida A450 LPS O-antigen seems to be identical to the one described for strains A449 and 80204 [12], which can be depicted as follows:

OAc

1

$\downarrow$

$\rightarrow 4)-\alpha-L-R h a p-(1 \rightarrow 3)-\beta-D-M a n p N A c-(1 \rightarrow$

3

$\uparrow$

1

$\alpha-\mathrm{D}-\mathrm{Glc} p$

\subsection{LPS O-Antigen Biosynthesis Gene Cluster (wbsalmo)}

An A. salmonicida A450 cosmid-based genomic library was constructed and introduced into E. coli DH5 $\alpha$ as previously described for other Aeromonas strains [15]. As we and others reported, A. salmonicida LPS O-antigen contains rhamnose. Thus, we used previously constructed DNA probes from $A$. hydrophila strain AH-3 rmlA and $B$ genes (two biosynthetic rhamnose genes, [16]) due to their high DNA sequence conservation among Aeromonas strains, and screened the A. salmonicida A450 genomic library by colony Southern blot. Several tetracycline-resistant clones able to cross react with both probes were isolated and sequences flanking the DNA inserted were determined by using oligonucleotides complementary to the pLA2917 [15] cosmid. To complete the nucleotide sequence (GenBank KR704893) other sequence-derived oligonucleotides were designed by us, purchased (Sigma-Aldrich) and used. Analysis of the sequenced regions showed 26 complete putative open reading frames (ORFs) transcribed in the same direction, being 13 of them (ORF1 to 5 and ORF18 to 25) genes involved in the LPS O-antigen biosynthesis ( $w b_{\text {salmo }}$ cluster) as indicated in Figure 1 (in yellow). 


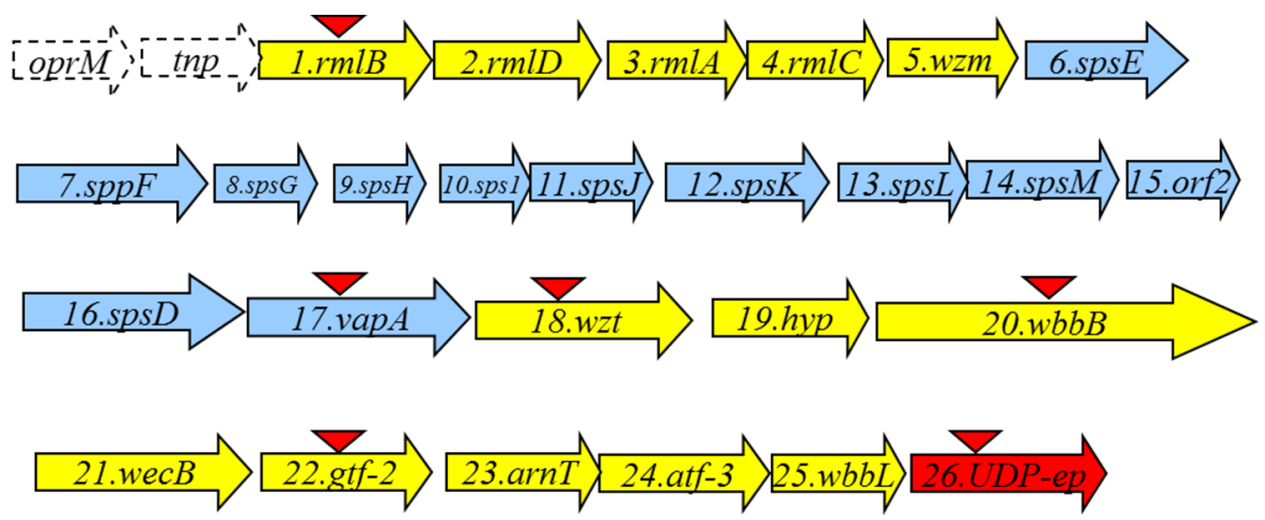

Figure 1. The A. salmonicida A450 LPS O-antigen ( $w b_{\text {salmo }}$ ) in yellow and S-layer cluster in blue open reading frames (ORFs) detected as complete genes. The genes, numbered according to the ORF number, were named according to the similarity found by their encoding products with proteins of well characterized functions. The UDP-ep gene (in red) does not belong to any of both clusters. The orf named tnp is encoding a putative transposase protein with a DDE domain from superfamily endonuclease. The oprM gene is incompletely sequenced and it should be noticed that it is also adjacent to the $w b$ O34-antigen LPS from strain AH-3 previously characterized [16]. Triangles indicate the mutants obtained.

The putative transposase protein showed a DDE domain from a superfamily of endonucleases. This domain contains three carboxylate residues that are believed to be responsible for coordinating metal ions needed for catalysis. The catalytic activity of this enzyme involves DNA cleavage at a specific site followed by a strand transfer reaction.

We observed several ORFs (6 to 17), indicated in blue (Figure 1), between the genes involved in the LPS biosynthesis that belong to a type II secretion system (T2SS) plus the structural gene vapA (ORF17) which encodes the surface A-layer protein. It seems logical that these ORFs are genes that encode for the production and export/assembly of the A. salmonicida A-layer characteristic from these strains. Interestingly, the insertion point of the A-layer genes is immediately downstream of a gene encoding for a Wzm putative protein. Downstream of the A-layer genes, a complete ORF encoding a Wzt putative protein was observed. Wzm and Wzt proteins are characteristics of an ABC-2 type transporter. Finally, we found a gene (ORF26), labeled in red (Figure 1), that encodes for a NAD-dependent dehydratase or UDP-sugar epimerase (named accordingly $U D P-e p$ ). This gene does not initially belong to the $w b_{\text {salmo }}$ cluster, because its mutation does not abolish the LPS O-antigen (see next section). Sequence analysis of the $w b_{\text {salmo }}$ gene cluster revealed a conserved JUMPstart sequence with the 8 bp ops (operon polarity suppressor) sequence (GGCGGTAG) $119 \mathrm{bp}$ upstream of the ORF1. The ops sequence is recognized by the bacterial antiterminator $\mathrm{RfaH}$, which can be recruited by the transcription elongation complex to reduce pausing and termination at intergenic sites of polycistronic operons, allowing RNA polymerase to finalise transcription of the distal genes in large operons [17,18].

Analysis of ORFs from $w b_{\text {salmo }}$ and S-layer clusters with their predicted function based on their homology to proteins of known function is shown in Table 2. 
Table 2. Characteristics of the A. salmonicida A450 O-antigen LPS ( $w b_{\text {salmo}}$ ) and A-layer cluster ORFs.

\begin{tabular}{|c|c|c|c|c|c|}
\hline ORF & $\begin{array}{l}\text { Protein } \\
\text { Name }\end{array}$ & $\begin{array}{c}\text { Protein Size } \\
\text { (in Amino Acid } \\
\text { Residues) } \\
\end{array}$ & Predicted Function & Homologous Protein with Known Function & $\begin{array}{l}\text { Percentage in Amino Acid } \\
\text { Identity/Similarity }\end{array}$ \\
\hline \multicolumn{6}{|c|}{ Inserted S-layer protein cluster } \\
\hline 18 & Wzt & 438 & $\mathrm{ABC}$ transporter ATP binding protein & Wzt multispecies Aeromonas & $100 / 100$ \\
\hline 19 & Hyp & 216 & Hypothetical protein with domain Sulfotransferase & Sulfotransferase Vibrio cholerae & $38 / 54$ \\
\hline 20 & WbbB & 1122 & $N$-acetyl glucosaminyl transferase & WbbB Klebsiella pneumonaie & $63 / 77$ \\
\hline 21 & WecB & 370 & UDP- $N$-acetyl glucosamine 2-epimerase & WecB Serratia marcescens & $100 / 100$ \\
\hline 22 & Gtf-2 & 355 & Glycosyl transferase & Glycosyl transferase family group 2 Vibrio choleare & $78 / 91$ \\
\hline 23 & ArnT & 457 & $\begin{array}{l}\text { Hypothetical protein with ArnT } \\
\text { (4-amino-4-deoxy-L-arabinose transferase) domain }\end{array}$ & Hypothetical protein multispecies Aeromonas & $100 / 100$ \\
\hline 24 & Atf-3 & 348 & Acetyl transferase family 3 & Acetyltransferase Serratia marcescens & $45 / 65$ \\
\hline 25 & WbbL & 288 & Rhamnosyl transferase & $\begin{array}{l}\text {-Glucosyl transferase family } 2 A \text {. veronii } \\
\text {-Rhamnosyl transferase } E \text {. coli }\end{array}$ & $\begin{array}{l}-100 / 100 \\
-43 / 67\end{array}$ \\
\hline 26 & UDP-ep & 318 & $\begin{array}{l}\text { NAD-dependent dehydratase or } \\
\text { UDP-sugar epimerase }\end{array}$ & $\begin{array}{l}\text { NAD-dependent dehydratase or } \\
\text { UDP-sugar epimerase multispecies Aeromonas }\end{array}$ & $100 / 100$ \\
\hline \multicolumn{6}{|c|}{ A-layer protein cluster } \\
\hline 6 & SpsE & 552 & S-layer secretion system protein $\mathrm{E}$ & Type II secretion system (T2SS) protein E A. salmonicida & $100 / 100$ \\
\hline 7 & $\mathrm{SpsF}$ & 395 & S-layer secretion system protein $\mathrm{F}$ & Type II secretion system(T2SS) protein F A. salmonicida & $100 / 100$ \\
\hline 8 & SpsG & 143 & S-layer secretion system protein $\mathrm{G}$ & Type II secretion system (T2SS) protein G A. salmonicida & $97 / 99$ \\
\hline 9 & $\mathrm{SpsH}$ & 131 & S-layer secretion system protein $\mathrm{H}$ & Type II secretion system (T2SS) protein H A. salmonicida & $96 / 98$ \\
\hline 10 & SpsI & 132 & S-layer secretion system protein I & Type II secretion system (T2SS )protein I A. salmonicida & $99 / 100$ \\
\hline 11 & Sps $J$ & 235 & S-layer secretion system protein $\mathrm{J}$ & Type II secretion system (T2SS) protein J A. salmonicida & $94 / 98$ \\
\hline 12 & SpsK & 288 & S-layer secretion system protein $\mathrm{K}$ & Type II secretion system (T2SS) protein $\mathrm{K}$ A. salmonicida & $100 / 100$ \\
\hline 13 & SpsL & 371 & S-layer secretion system protein $\mathrm{L}$ & Type II secretion system (T2SS) protein L A. salmonicida & $94 / 95$ \\
\hline
\end{tabular}




\subsection{Mutant Isolation and Characterization}

As described in Materials and Methods section, we obtained in-frame mutants in ORFs 1, 17, 18, 20,

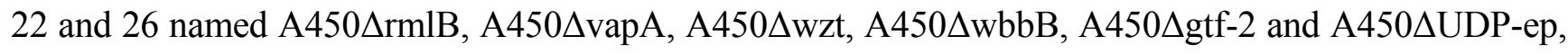

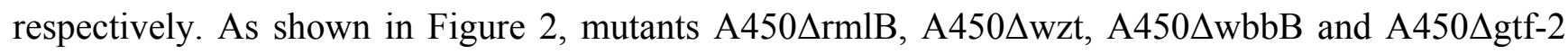
were unable to produce LPS O-antigen when analyzed in a SDS-PAGE gel. However, A450 $\Delta$ vapA and A450 $\Delta$ UDP-ep mutants showed in the same gels an identical LPS profile as the wild-type strain with O-antigen ladder repetitions.

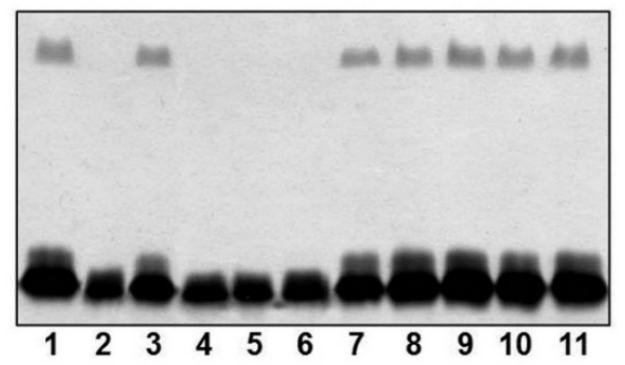

Figure 2. LPS analysed by SDS-PAGE (12\%) and silver stained from A. salmonicida A450

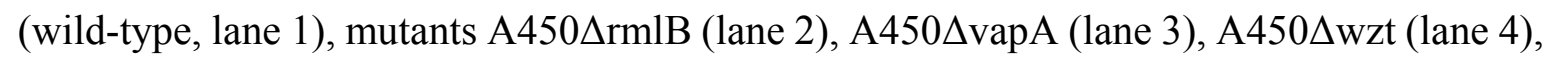

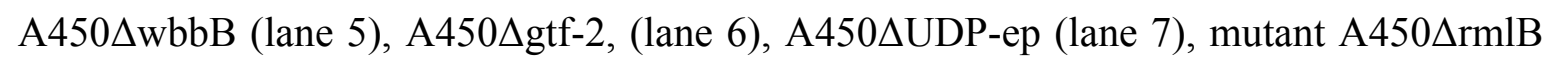
complemented with A450rmlB (lane 8), mutant A450 $\Delta$ wzt complemented with A450wzt (lane 9), mutant $\mathrm{A} 450 \Delta \mathrm{wbbB}$ complemented with $\mathrm{A} 450 w b b B$ (lane 10), and mutant A450 $\Delta$ gtf-2 complemented with A450gtf-2 (lane 11).

We obtained outer-membrane proteins (OMp) from A450 $\Delta$ vapA mutant as described in Materials and Methods. Analysis by SDS-PAGE gels showed the lack of the major protein band of approximately $49 \mathrm{kDa}$ compared with the wild type (Figure $3 \mathrm{~A}$ ). This band reacts with specific serum anti-VapA protein in Western blot analysis (Figure 3B). Mutant A450 4 UDP-ep showed no changes in OMp.

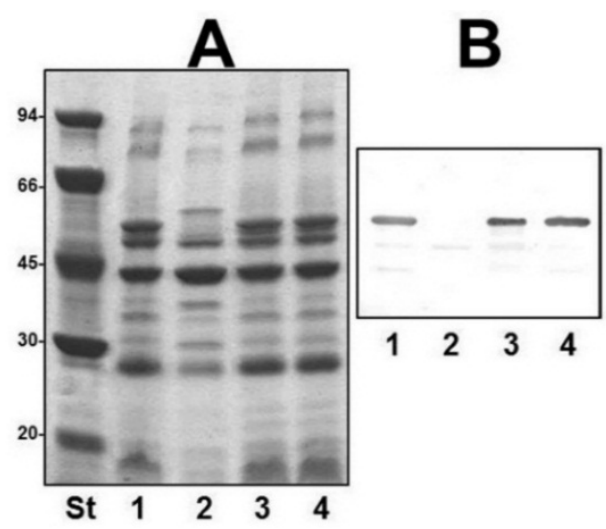

Figure 3. (A) Outer membrane proteins, and (B) Western blot using antiserum against A-layer protein (anti-VapA protein) of strains: A450 (wild type, lane 1), mutant A450 $\Delta$ vapA

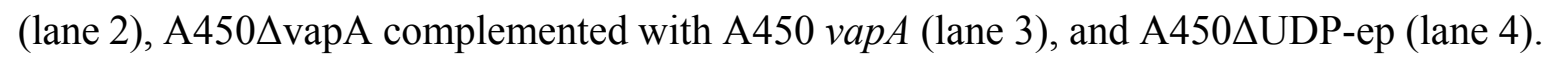
St, molecular weight standard. 
The reintroduction of the corresponding wild-type genes in A450 $\Delta \mathrm{rmlB}, \mathrm{A} 450 \Delta \mathrm{wzt}, \mathrm{A} 450 \Delta \mathrm{wbbB}$, and A450 $\Delta$ gtf-2 fully restored the LPS profile of the wild-type strain in silver-stained SDS gels (Figure 2). A similar situation was observed when wild-type vapA was reintroduced in mutant A450 $\Delta$ vapA, the presence in the OMp profile of the $49 \mathrm{kDa}$ protein reacting with specific serum anti-A protein was restored (Figure 3).

\subsection{Different A. salmonicida Subspecies Strains}

When we analyzed the LPS by SDS-PAGE gels from different $A$. salmonicida subsp. salmonicida strains, we found an identical O-antigen LPS profile in all of them. However, when we analyzed the LPS profile in gels from different $A$. salmonicida subspecies strains, we found that the strains belonging to A. salmonicida subsp. pectinolytica lack the characteristic LPS O-antigen homogeneous band, while the rest of the subspecies showed it (Figure 4A).

The analysis of the OMp from different $A$. salmonicida subspecies strains by Western blot using specific anti-A protein antiserum is shown in Figure 4B. With the exception of two strains identified as A. salmonicida subsp. pectinolytica, all other strains produced a band of approximately $49 \mathrm{kDa}$ which reacted with antiserum against A-protein (Figure 4B).

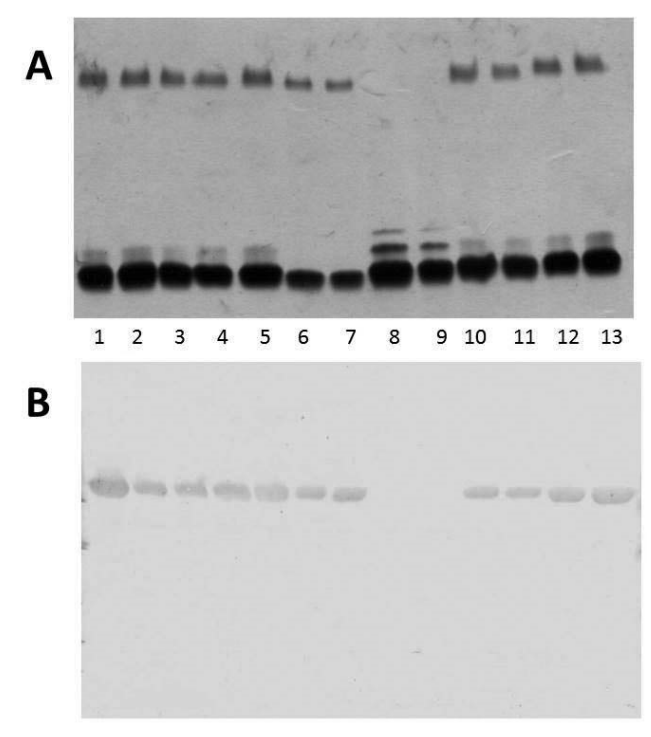

Figure 4. (A) LPS analysed by SDS-PAGE (12\%) and silver stained from different A. salmonicida subspecies strains. Lane 1, subsp. salmonicida A450; lane 2, subsp. masoucida strain CECT896T; lane 3, subsp. masoucida strain AS60; lane 4, subsp. achromogenes strain CECT4238; lane 5, subsp. achromogenes strain CECT895T; lane 6, subsp. achromogenes strain AS46; lane 7, subsp. achromogenes strain AS102; lane 8, subsp. pectinolytica strain CECT5752T; lane 9, subsp. pectinolytica strain CECT5753; lane 10, subsp. smithia strain CECT5179; lane 11, subsp. smithia strain AS74; lane 12, subsp. salmonicida strain CECT894; and lane 13, subsp. salmonicida strain CECT4235; (B) Western blot analysis using specific serum anti-A protein and OMp from different A. salmonicida subspecies strains. Lanes as in A. 


\subsection{Analysis of Fully Sequenced Genomes}

When we inspected all the currently available Aeromonas salmonicida genomes, we found two for A. salmonicida subsp. salmonicida strains A449 and 01-B526, one for A. salmonicida subsp. achromogenes strain AS03, one for A. salmonicida subsp. masoucida strain NBRC 13784, one for A. salmonicida subsp. pectinolytica strain $34 \mathrm{melT}$, and none for A. salmonicida subsp. smithia. Despite the different genome annotations (in part because these DNA regions had not been properly studied) with a more accurate comparative genomic analysis, we can conclude that in all the A. salmonicida genomes, besides the one for $A$. salmonicida subsp. pectinolytica strain $34 \mathrm{melT}$, the $w b_{\text {salmo }}$ is nearly identical. Furthermore, the chromosomal location between the oprM and UDP-ep genes is conserved among them. However, in the A. salmonicida subsp. pectinolytica strain $34 \mathrm{melT}$ genome, we found a putative $w b$ cluster completely different. Briefly, the $r m l$ genes for rhamnose biosynthesis are not together, wzm-wzt are not present, and besides finding an oprM gene upstream, downstream of the $r m l C$ seems to be a region with partial genes and encoded bacteriophage proteins (see Figure 5 and Table 3 ).

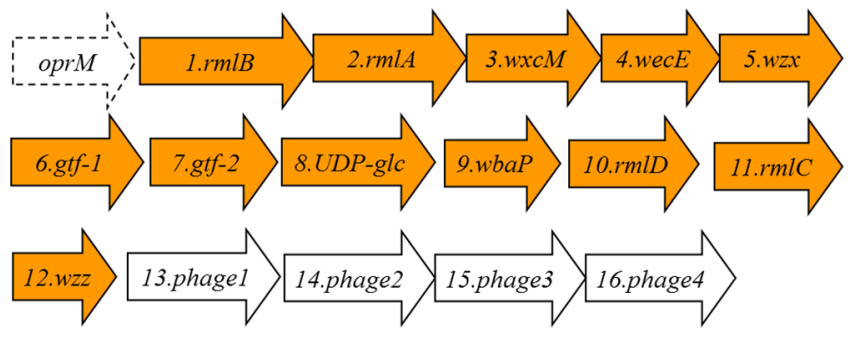

Figure 5. The A. salmonicida subsp. pectinolytica strain 34melT putative genes for the LPS $\mathrm{O}$-antigen cluster in orange. The genes, numbered according to the ORF number, were named according to their similarity, as found by their encoding proteins, with proteins of well characterized functions.

Table 3. Characteristics of the proteins encoded by the ORFs detected in their LPS O-antigen cluster.

\begin{tabular}{cccl}
\hline ORF & $\begin{array}{c}\text { Protein } \\
\text { Name }\end{array}$ & $\begin{array}{c}\text { Protein Size in Amino } \\
\text { Acid Residues }\end{array}$ & Predicted Function \\
\hline 1 & RmlB & 361 & dTDP-glucose-4-6-dehydratase RmlB \\
2 & RmlA & 289 & Glucose-1-phosphate thymidylyl transferase RmlA \\
3 & WxcM & 137 & dTDP-6-deoxy-3,4-keto-hexulose isomerase. \\
4 & WecE & 367 & aminotransferase family, WecE \\
5 & Wzx & 416 & O-antigen flippase \\
6 & Gtf-1 & 140 & glycosyl transferase group 1 \\
7 & Gtf-2 & 249 & glycosyl transferase group 2 \\
8 & UDP-glc & 388 & UDP-glucose 6-dehydrogenase \\
9 & WbaP & 423 & polyprenyl glycosyl phosphotransferase \\
10 & RmlD & 296 & dTDP-4-dehydro rhamnose reductase \\
11 & RmlC & 176 & dTDP-4-dehydro rhamnose 3,5-epimerase \\
12 & Wzz & 202 & O-antigen size regulator protein \\
13 & Phage1 & 113 & Phage terminase 1 protein \\
14 & Phage2 & 283 & phage portal protein \\
15 & Phage3 & 141 & phage prohead peptidase \\
16 & Phage4 & 398 & putative phage phi-C31 gp36 major capsid-like protein \\
\hline
\end{tabular}




\section{Discussion}

The A. salmonicida A450 LPS O-antigen gene cluster ( $w b_{\text {salmo }}$ ) showed a $\mathrm{G}+\mathrm{C}$ percentage of approximately $49.1 \%$, which is significantly lower than the expected $(59 \%-63 \%)$ for this species. This is characteristic of the $w b$ clusters from different bacteria that can be $10 \%$ lower in $\mathrm{G}+\mathrm{C}$ than the species average. Initially the encoded proteins showed some consistency with the chemical structure of the O-antigen LPS. ORF1 to 4 (in order RmlB, D, A and C, respectively) are the biosynthetic proteins for dTDP-rhamnose production, ORF21 (WecB) is the enzyme that converts UDP-GlcNAc into UDP-ManAc [19], and rhamnose, ManAc, and Glc are the monosaccharide components of the LPS $\mathrm{O}$-antigen. There is no need for UDP-Glc specific genes. Three glycosyl transferases seem to be involved in the biosynthesis of the O-antigen repeating unit (ORF20, named WbbB; ORF22, named Gtf-2 and ORF25, named WbbL). WbbL is a presumptive rhamnosyl transferase, while the WbbB showed a HexNAc transferase domain (here probably acetyl- $N$-mannosamine), and Gtf-2 could be the transferase for the Glc incorporation to the LPS O-antigen repeating unit. There is also an acetyl transferase (ORF24 named Atf-3) which is in agreement with the acetylated rhamnose of the LPS O-antigen.

ORF5 and 18 were similar to an ABC-2 type transport system integral membrane and an ATP-binding protein, respectively (Table 2). The ORF5 protein hydrophobicity analysis and identification of the putative transmembrane domains [20] indicate that it is an integral membrane protein. The ORF18 protein contains the sequence GHNGAGKS (amino acid residues 57 to 64) which corresponds to the Walker box A, a motif present in ATP-binding proteins, as well as the ABC transporter family signature YSSGMYVRLAFAVQA (amino acid residues 162-175). Thus, ORF5 and 18 were named wzm and $w z t$ respectively, despite the fact that they are usually found adjacent. Two main known pathways for O-antigen export have been established [9], the Wzy-dependent pathway for heteropolysaccharide structures and the ABC-2 transporter-dependent pathway mainly for homopolysaccharides or disaccharides. The presence of complete Wzm (ORF5) and Wzt (ORF18) showed that this LPS O-antigen belongs to the second pathway and represents the first example of an O-antigen LPS polysaccharide with three different monosaccharides in their repeating unit assembled by this pathway. Between the Wzm (ORF5) and Wzt (ORF18), we found the genes responsible for the biosynthesis and assembly of the S-layer (named A-layer), (Figure 1 and Table 2). The S-layer-encoding genes included a large group of T2SS genes plus some encoding hypothetical proteins related to this specific S-layer T2SS system (ORF6 to 16), and the last gene encoding the unique protein that forms the A-layer (vapA, ORF17) characteristic of $A$. salmonicida strains. The insertion point of this genomic cluster seems to be in the intergenic region between the genes encoding for a Wzm protein, located just upstream of the S-layer genes, and the gene encoding a Wzt protein (ORF18, as previously indicated). Accordingly to this, the A450 $\triangle$ vapA in frame mutant showed identical LPS profile as the wild-type strain with the same O-antigen profile in SDS-PAGE gels, but lacked the VapA protein being then unable to produce the A-layer. Mutants A450 $\Delta \mathrm{rmlB}, \mathrm{A} 450 \Delta \mathrm{wzt}, \mathrm{A} 450 \Delta \mathrm{wbbB}$, and $\mathrm{A} 450 \Delta \mathrm{gtf}-2$, when analyzed in an SDS-PAGE gel, were unable to produce LPS O-antigen. However, the A450 $\triangle$ UDP-ep mutant showed an identical LPS profile as the wild-type strain with the presence of O-antigen in the LPS. Then, we concluded that ORF22 (UDP-ep) does not belong to the $w b_{\text {salmo, }}$, because it seems not to be need for LPS O-antigen biosynthesis. 
It is characteristic of the LPS O-antigen disaccharides assembled and exported thought an ABC-2 type transporter to contain a large protein (WbbB), like in K. pneumoniae O12 [21,22], that shows two clear domains. The first domain, in K. pneumoniae WbbB consisted of a condensation or capsule polysaccharide biosynthesis domain from amino acid residues 125 to 300; and a second domain with glycosyltransferase activity from GT1 family (625 to 825 amino acid residues) related to HexNAc transferases [21]. The A. salmonicida WbbB (ORF20) is larger than the one in Klebsiella, and showed three domains: capsule polysaccharide biosynthesis (130 to 290 amino acid residues), a glycosyltransferase activity from GT1family 1 (500 to 825 amino acid residues), and an additional glycosyltransferase activity domain from GT2 family (850 to 1050 amino acid residues). The fact there is an additional glycosyltransferase domain in the $A$. salmonicida $\mathrm{WbbB}$ seems to be in accordance with the O-antigen being a trisaccharide instead of a disaccharide.

At this moment, not much can be said about the hypothetical protein with a sulfotransferase domain (ORF 19, named Hyp), no such residue seems to be found in the chemical structure of the LPS O-antigen in these strains [10,12], and also about the hypothetical protein (ORF23 named ArnT) with a 4-amino-4-deoxy-L-arabinose transferase domain. However, it is true that in Aeromonas has been described the presence of a 4-amino-4-deoxy-L-arabinose in the lipid A [23]. Both genes encoding these

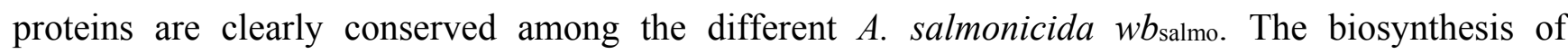
O-antigens starts with the assembly of monomers on an undecaprenol phosphate (lipid carrier), before their incorporation into the LPS molecules, by enzymes that can be present or not in the $w b$ gene

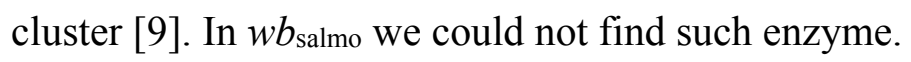

When we inspected and deeply studied all the currently available A. salmonicida genomes, we found that the $w b_{\text {salmo }}$ was conserved in all of the different subspecies with identical gene location besides in A. salmonicida subsp. pectinolytica. This fact is in full agreement with the LPS profiles in SDS-PAGE obtained for the different $A$. salmonicida strains from several subspecies. Sequence analysis of the A. salmonicida subsp. pectinolytica $w b$ gene cluster from strain 34 melT revealed that the LPS O-antigen seems to be exported through a Wzx-Wzy pathway and not an ABC-2 transporter-dependent pathway. However, besides the presence of the typical genes encoding the Wzx and Wzz proteins, no gene encoding a Wzy protein could be found in this cluster. Wzy mutants showed only a single O-antigen repeating unit [9] and, in the case of the LPS profile of A. salmonicida subsp. pectinolytica strains, it seems that a single O-antigen unit could be observed. A. salmonicida subsp. pectinolytica strains clearly show a different O-antigen LPS compared to the other subspecies and lack the A-layer according to our results. No such A-layer protein encoded by vapA gene could be detected by blot hybridization or PCR using appropriate DNA primers (Figure 6). This gene could not be found in the complete genome of $A$. salmonicida subsp pectinolytica strain $34 \mathrm{melT}$.

These two features, lack of $w b_{\text {salmo }}$ and A-layer, are in agreement with the fact that atypical $A$. salmonicida subsp. pectinolytica strains are the only ones not found as pathogens in a wide variety of fish species [24]. Besides, no genome is available for $A$. salmonicida subsp. smithia. Our results suggest that the $w b_{\text {salmo }}$ should also be conserved in these strains, according to the LPS profile in SDS-PAGE gels. 


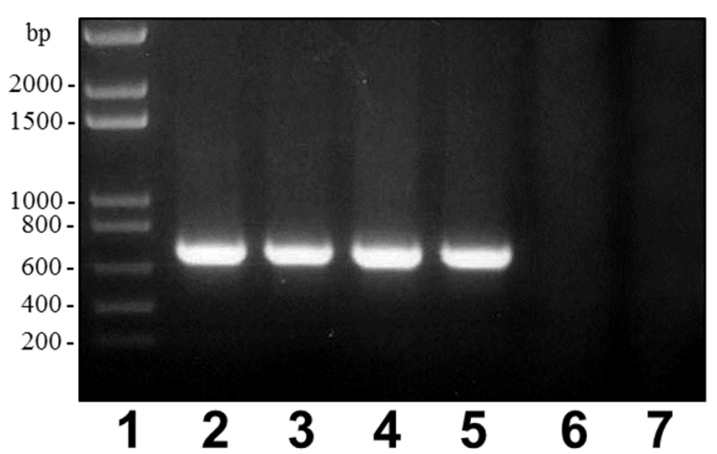

Figure 6. PCR amplified band (696 bp) with primers VapA-for: 5'-ATCGACAGCAA TGGCAAG-3' and VapA-rev: 5'-ATCACGGGTGAGGATGAAG-3' and A. salmonicida genomic DNAs from strains: subspecies salmonicida A450 (lane 2), subspecies masoucida CECT4235 (lane 3), subspecies achromogenes CECT4238 (lane 4), subspecies smithia CECT5179 (lane 5), subspecies pectinolytica CECT5752T (lane 6), and subspecies pectinolytica CECT5753 (lane 7). Lane 1, DNA molecular weight standard.

\section{Materials and Methods}

\subsection{Bacterial Strains, Plasmids and Growth Conditions}

The bacterial strains and plasmids used in this study are listed in Table 4. E. coli strains were grown on Luria-Bertani (LB) Miller broth and LB Miller agar at $37^{\circ} \mathrm{C}$, while Aeromonas salmonicida strains were grown either in tryptic soy broth (TSB) or agar (TSA) at $20{ }^{\circ} \mathrm{C}$. Ampicillin $\left(100 \mu \mathrm{g} \cdot \mathrm{mL}^{-1}\right)$, chloramphenicol $\left(25 \mu \mathrm{g} \cdot \mathrm{mL}^{-1}\right)$, tetracycline $\left(20 \mu \mathrm{g} \cdot \mathrm{mL}^{-1}\right)$, kanamycin $\left(50 \mu \mathrm{g} \cdot \mathrm{mL}^{-1}\right)$, nalidixic acid $\left(20 \mu \mathrm{g} \cdot \mathrm{mL}^{-1}\right)$ and gentamycin $\left(20 \mu \mathrm{g} \cdot \mathrm{mL}^{-1}\right)$ were added to the different media when required. A. salmonicida AS46, AS60, AS74, and AS102 were kindly provided by Prof. Brian Austin (University of Stirling, Scotland).

\subsubsection{General DNA Methods}

General DNA manipulations were done essentially as previously described [30]. DNA restriction endonucleases, T4 DNA ligase, E. coli DNA polymerase (Klenow fragment), and alkaline phosphatase were used as recommended by the Sigma-Aldrich (St Louis, MO, USA).

\subsubsection{DNA Sequencing and Computer Analysis of Sequence Data}

Double-stranded DNA sequencing was performed by using the dideoxy-chain termination method [31] from PCR amplified DNA fragments with the ABI Prism dye terminator cycle sequencing kit (PerkinElmer, Barcelona, Spain). Oligonucleotides used for genomic DNA amplifications and DNA sequencing were purchased from Sigma-Aldrich (St Louis, MO, USA). Deduced amino acid sequences were compared with those of DNA translated in all six frames from non-redundant GenBank and EMBL databases by using the BLAST [32] network service at the National Center for Biotechnology Information and the European Biotechnology Information. ClustalW was used for multiple-sequence alignments [33]. 
Table 4. Bacterial strains and plasmids used.

\begin{tabular}{|c|c|c|}
\hline Strain or Plasmid & Relevant Characteristics & $\begin{array}{l}\text { Reference } \\
\text { or Source }\end{array}$ \\
\hline \multicolumn{3}{|c|}{ E. coli strains } \\
\hline DH5a & $\mathrm{F}^{-}$end $A$ hsdR17 $\left(\mathrm{rK}^{-} \mathrm{mK}^{+}\right)$supE44 thi-1 recAl gyr-A96_80lacZM15 & [25] \\
\hline MC1061 & thi thr1 leu6 proA2 his4 argE2 lacY1 galK2 ara14 xyl5, supE44, $\lambda$ pir & [26] \\
\hline \multicolumn{3}{|c|}{ A. salmonicida strains } \\
\hline $\mathrm{A} 450$ & Wild type, subsp. salmonicida & [27] \\
\hline A450nal ${ }^{\mathrm{R}}$ & A450 nalidixic acid resistant & [27] \\
\hline $\mathrm{A} 450 \Delta \mathrm{rmlB}$ & A450 rmlB in frame mutant unable to produce LPS O-antigen & This study \\
\hline 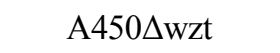 & A450 wzt in frame mutant unable to produce LPS O-antigen & This study \\
\hline $\mathrm{A} 450 \Delta \mathrm{wbbB}$ & A450 $w b b B$ in frame mutant unable to produce LPS O-antigen & This study \\
\hline $\mathrm{A} 450 \Delta \mathrm{gtf}-2$ & A450 $\mathrm{gtf}-2$ in frame mutant unable to produce LPS O-antigen & This study \\
\hline $\mathrm{A} 450 \Delta$ vapA & $\begin{array}{c}\text { A450 vapA in frame mutant, unable to produce A-layer but able to } \\
\text { produce LPS O-antigen }\end{array}$ & This study \\
\hline A450 $\Delta$ UDP-ep & $\begin{array}{l}\text { A450 UDP-ep in frame mutant, able to produce } \\
\text { LPS O-antigen and A-layer }\end{array}$ & This study \\
\hline СЕСТ894 & Wild type, subsp. salmonicida & CECT \\
\hline CECT4235 & Wild type, subsp. salmonicida & CECT \\
\hline СЕСТ896T & Wild type, subsp. masoucida & CECT \\
\hline AS60 & Wild type, subsp. masoucida & [28] \\
\hline CECT4238 & Wild type, subsp. achromogenes & CECT \\
\hline СЕCT895T & Wild type, subsp. achromogenes & CECT \\
\hline AS46 & Wild type, subsp. achromogenes & [28] \\
\hline AS102 & Wild type, subsp. achromogenes & [28] \\
\hline CECT5752T & Wild type, subsp. pectinolytica & CECT \\
\hline CECT5753 & Wild type, subsp. pectinolytica & CECT \\
\hline CECT5179 & Wild type, subsp. smithia & CECT \\
\hline AS74 & Wild type, subsp. smithia & [28] \\
\hline \multicolumn{3}{|c|}{ Plasmids } \\
\hline pGEMT easy & PCR generated DNA fragment cloning vector $A m p^{R}$ & Promega \\
\hline pBAD33-Gm & Arabinose-inducible expression vector, $\mathrm{Gm}^{\mathrm{R}}$ & {$[27,29]$} \\
\hline pDM4 & pir dependent with $s a c A B$ genes; oriR6K; $\mathrm{Cm}^{\mathrm{R}}$ & [27] \\
\hline pLA2917 & Cosmid vector, $\mathrm{Km}^{\mathrm{R}}, \mathrm{Tc}^{\mathrm{R}}$ & {$[15]$} \\
\hline
\end{tabular}

\subsubsection{Mutant and Plasmid Constructions, Mutant Complementation Studies}

The chromosomal in-frame A450 $\Delta \mathrm{rmlB}, \mathrm{A} 450 \Delta \mathrm{vapA}, \mathrm{A} 450 \Delta \mathrm{wzt}, \mathrm{A} 450 \Delta \mathrm{wbbB}, \mathrm{A} 450 \Delta \mathrm{gtf}-2$ and A450 $\Delta$ UDP-ep deletion mutants were constructed by allelic exchange as described by Milton et al. [26]. Plasmids were transferred to $A$. salmonicida strains as previously indicated [27]. To complete the allelic exchange, the integrated suicide plasmid was forced to recombine out of the chromosome by growing on agar plates containing $10 \%$ sucrose. Mutants were selected based on their survival on plates containing $10 \%$ sucrose and loss of the chloramphenicol resistant marker of vector pDM4. The mutations were confirmed by sequencing of the whole constructs in amplified PCR products. The primers used are shown in Table 5. 
Table 5. (A) Primers used in the construction of chromosomal in-frame deletion mutants. (B) Primers used for mutant complementation using vector pBAD33-Gm.

A

\begin{tabular}{|c|c|}
\hline Primers a,b & Amplified Fragment \\
\hline \multicolumn{2}{|l|}{$\mathrm{rmlB}$} \\
\hline A: 5'-CGCGGATCCCAAGTTCTGCCTGGTAT-3' & \multirow{2}{*}{$\mathrm{AB}(632 \mathrm{bp})$} \\
\hline B: 5'-TGTTTAAGTTTAGTGGATGGGTGCACCACCAGTGACAAG-3' & \\
\hline C: 5'-CCCATCCACTAAACTTAAACAAGTGGTGCCTACCAATCCT-3' & \multirow{2}{*}{$\mathrm{CD}(704 \mathrm{bp})$} \\
\hline \multirow[t]{2}{*}{ D: 5'-CGCGGATCCAACATCGGGTTTGCTCT-3' } & \\
\hline & $\mathrm{AD}(1312 \mathrm{bp})$ \\
\hline \multicolumn{2}{|l|}{ vapA } \\
\hline A: 5'-GAAGATCTGCCGATTCAGGTAAAACAG-3' & \multirow{2}{*}{$\mathrm{AB}(717 \mathrm{bp})$} \\
\hline B: 5'-TGTTTAAGTTTAGTGGATGGGGCTAATCACGACATCAGCA-3' & \\
\hline C: 5'-CCCATCCACTAAACTTAAACA GAAGGCGTGGATATTCAGA-3' & \multirow{2}{*}{$\mathrm{CD}(670 \mathrm{bp})$} \\
\hline \multirow[t]{2}{*}{ D: 5'-GAAGATCTAACGATCATCCATCTCTCG-3' } & \\
\hline & $\mathrm{AD}(1366 \mathrm{bp})$ \\
\hline \multicolumn{2}{|l|}{$w z t$} \\
\hline A: 5'-CGCGGATCCGAGCTGGCTGATCTCTTCA-3' & \multirow{2}{*}{$\mathrm{AB}(721 \mathrm{bp})$} \\
\hline B: 5'-TGTTTAAGTTTAGTGGATGGG GGAACGATAGATGGGAAATG-3' & \\
\hline C: 5'-CCCATCCACTAAACTTAAACAGATGTCGCCATGTTTCAAG-3' & \multirow{2}{*}{$\mathrm{CD}$ (653 bp) } \\
\hline \multirow[t]{2}{*}{ D: 5'-CGCGGATCCTGATTGGGCGAAAATA-3' } & \\
\hline & $\mathrm{AD}(1353 \mathrm{bp})$ \\
\hline \multicolumn{2}{|l|}{$w b b B$} \\
\hline A: 5'-CGCGGATCCTACTTGCCCGAGATACCAG-3' & \multirow{2}{*}{$\mathrm{AB}(659 \mathrm{bp})$} \\
\hline B: 5'-TGTTTAAGTTTAGTGGATGGGACCTAGCACGACCCAAAG-3' & \\
\hline C: 5'-CCCATCCACTAAACTTAAACAGTTAAGCAGGCGCTATTTG-3' & \multirow{2}{*}{$\mathrm{CD}(753 \mathrm{bp})$} \\
\hline \multirow[t]{2}{*}{ D: 5'-CGCGGATCCTACGATGCGATGTTACCAA-3' } & \\
\hline & AD (1391 bp) \\
\hline \multicolumn{2}{|l|}{$g t f-2$} \\
\hline A: 5'-CGCGGATCCGCACCTACGCAAATTTCTC-3' & \multirow{2}{*}{$\mathrm{AB}(722 \mathrm{bp})$} \\
\hline B: 5'-TGTTTAAGTTTAGTGGATGGG CACCGGTGAAAGATAAACC-3' & \\
\hline C: 5'-CCCATCCACTAAACTTAAACA TTTCATAATAGTGGCGATGC-3' & \multirow{2}{*}{$\mathrm{CD}(631 \mathrm{bp})$} \\
\hline \multirow[t]{2}{*}{ D: 5'-CGCGGATCCGACTGCCGTCTCTTTGAAC-3' } & \\
\hline & $\mathrm{AD}(1332 \mathrm{bp})$ \\
\hline \multicolumn{2}{|l|}{$U D P-e p$} \\
\hline A: 5'-CGCGGATCCTGGCGTTGAATAATGGAG-3' & \multirow{2}{*}{$\mathrm{AB}(646 \mathrm{bp})$} \\
\hline B: 5'-TGTTTAAGTTTAGTGGATGGG CTTACCAACAAACCCGTTG-3' & \\
\hline C: 5'-CCСATCCACTAAACTTAAACAAAGGCTCAGAGGCGATTAC-3' & \multirow[t]{2}{*}{$\mathrm{CD}(771 \mathrm{bp})$} \\
\hline D: 5'-CGCGGATCCACCATCCCCCATAAAGAT-3' & \\
\hline & $\mathrm{AD}(1395 \mathrm{bp})$ \\
\hline
\end{tabular}


Table 5. cont.

\begin{tabular}{|c|c|c|}
\hline \multicolumn{3}{|c|}{ B } \\
\hline Plasmid & Primers & Amplified Fragment \\
\hline \multirow{2}{*}{ pBADGm-rmlB ${ }^{\mathrm{c}}$} & RmlB-FOR: 5'-TCCCCCGGGTTAAAAGCAGCGAACTG-3' & \multirow{2}{*}{$1380 \mathrm{bp}$} \\
\hline & RmlB-REV: 5'-GCTCTAGACGCTGGAGTCAAAATCAAC-3' & \\
\hline \multirow{2}{*}{ pBADGm-vap $A^{\mathrm{c}}$} & VapA-FOR: 5'-TCCCCCGGGTGATCAACGGATAGGTTCAA-3' & \multirow{2}{*}{$1666 \mathrm{bp}$} \\
\hline & VapA-REV: 5'-GCTCTAGAAGGGAACAAATGAAACTGCT-3' & \\
\hline \multirow{2}{*}{ pBADGm- $w z t^{\mathrm{c}}$} & Wzt-FOR: 5'-TCCCCCGGGTGACCACAGCCCTTATTTC-3' & \multirow{2}{*}{$1473 \mathrm{bp}$} \\
\hline & Wzt-REV: 5'-GCTCTAGATGCAGTAGTCCCACCTTTT-3' & \\
\hline \multirow{2}{*}{ pBADGm- $w b b B^{\mathrm{d}}$} & WbbB-FOR: 5'GGAATTCTAAGCTCACGGTTGCACAG-3' & \multirow{2}{*}{$3689 \mathrm{bp}$} \\
\hline & WbbB-REV: 5'-TCCCCCGGGATAACCGGAGCCATTTTGAT-3' & \\
\hline \multirow{2}{*}{ pBADGm-gtf $2^{c}$} & gtf2-FOR: 5'-TCCCCCGGGATGGCTAAAGGTTCTTCACC-3' & \multirow{2}{*}{$1269 \mathrm{bp}$} \\
\hline & gtf2-REV: 5'-GCTCTAGACATGACTGAAATACCCTGGA-3' & \\
\hline
\end{tabular}

${ }^{\mathrm{a}}$ Italic letters show overlapping regions. ${ }^{\mathrm{b}}$ Underlined letters show BamHI or BglII restriction site. ${ }^{\mathrm{c}}$ Primers contain SmaI(bold) and XbaI(underlined), the PCR amplified product was ligated to SmaI-XbaI digested pBAD33-Gm. ${ }^{\text {d }}$ Primers contain EcoRI (doubleunderlined) and SmaI(bold), the PCR amplified product was ligated to EcoRI-SmaI digested pBAD33-Gm.

For complementation studies, the $A$. salmonicida A450 rmlB, vapA, wzt, wbbB, and gtf-2 genes were PCR amplified using appropriate oligonucleotides obtained from the sequenced clones and chromosomal A450 DNA as template, ligated to plasmid pGEMT (Promega), and transformed into E. coli DH5 $\alpha$. After checked, the corresponding genes were subcloned on plasmid pBAD33-Gm (Table 5) with an arabinose-inducible and glucose-repressible promoter [27,29]. Induction was obtained by adding L-arabinose to a final concentration of $0.2 \%(w / v)$. Plasmids were transferred to A. salmonicida strains as previously indicated [27].

\subsubsection{LPS Characterization and SDS-PAGE}

LPS was obtained after proteinase $\mathrm{K}$ digestion of whole cells [34] for screening purposes. LPS samples were separated by sodium dodecyl sulfate-polyacrylamide gel electrophoresis (SDS-PAGE) and visualized by silver staining as previously described [34].

\subsubsection{LPS Isolation and O-Deacetylation}

Cells ( 3 g dried weight) were digested with DNase, RNase (24 h, 3 mg each) and Proteinase K (36 h, $3 \mathrm{mg})$ in $25 \mathrm{mM}$ Tris- $\mathrm{HCl}$ buffer $\mathrm{pH} 7.63$ containing $2 \mathrm{mM} \mathrm{CaCl}_{2}(30 \mathrm{~mL})$, the suspension was dialysed against distilled water and freeze-dried. Digested cells were extracted with aqueous $45 \%$ phenol at $68{ }^{\circ} \mathrm{C}[14]$, the extract was dialysed against tap water without separation of the layers, residual cells were removed by centrifugation, and the supernatant was freeze-dried to give lipopolysaccharide sample. An aliquot $(150 \mathrm{mg})$ was degraded with $0.1 \mathrm{M}$ sodium acetate buffer $\mathrm{pH} 4.2$ for $4 \mathrm{~h}$ at $100{ }^{\circ} \mathrm{C}$, the lipid precipitate was removed by centrifugation $(13,000 \times \mathrm{g}, 20 \mathrm{~min})$, and high-molecular-mass O-polysaccharide $(40 \mathrm{mg})$ was isolated from the supernatant by gel-permeation chromatography on a column $(50 \times 2.5 \mathrm{~cm})$ of Sephadex G-50 Superfine in pyridinium acetate buffer $(4 \mathrm{~mL}$ pyridine and $10 \mathrm{~mL}$ HOAc in $1 \mathrm{~L}$ water) using a Knauer differential refractometer (Knauer, Germany) for monitoring. The 
polysaccharide was deacetylated by heating with aqueous $12 \%$ ammonia $(2 \mathrm{~mL})$ for $3 \mathrm{~h}$ at $60{ }^{\circ} \mathrm{C}$, ammonia was removed by stream of air, and the remaining solution was freeze-dried.

Sugar analysis and Electrospray liquid chromatography mass spectrometry analysis. For sugar analysis, a polysaccharide sample (1 mg) was hydrolyzed with $2 \mathrm{M} \mathrm{CF}_{3} \mathrm{CO}_{2} \mathrm{H}\left(100{ }^{\circ} \mathrm{C}, 4 \mathrm{~h}\right)$, the monosaccharides were conventionally converted into the alditol acetates [35] and analyzed by GLC on a Varian 3700 chromatograph (Varian Inc., Palo Alto, CA, USA) equipped with a fused-silica gel SPB-5 column using a temperature gradient from $150{ }^{\circ} \mathrm{C}(3 \mathrm{~min})$ to $320{ }^{\circ} \mathrm{C}$ at $5^{\circ} \mathrm{min}^{-1}$. The absolute configurations of the monosaccharides were determined as described [36], using the same GLC conditions as in sugar analysis.

Mass spectrometry studies of purified O-polysaccharide were performed in the negative ion mode using a microTOF II instrument (Bruker Daltonics). A sample of the O-polysaccharide $\left(\sim 50 \mathrm{ng} \cdot \mu \mathrm{L}^{-1}\right)$ was dissolved in a 1:1 $(v / v)$ water-acetonitrile mixture and sprayed at a flow rate of $3 \mu \mathrm{L} \cdot \mathrm{min}^{-1}$. Capillary entrance voltage was set to $4.5 \mathrm{kV}$ and exit voltage to $-150 \mathrm{~V}$; drying gas temperature was $180^{\circ} \mathrm{C}$.

\subsubsection{OM Protein and S-Layer Isolation and Characterization}

Outer membranes $(\mathrm{OM})$ were obtained by incubating membrane suspensions with 3\% Sarkosyl in $20 \mathrm{mM}$ TrisHCl buffer ( $\mathrm{pH} \mathrm{8.0)}$ ) for $20 \mathrm{~min}$ at room temperature, as previously described [37]. Protein was analysed by SDS-PAGE and separated protein bands were visualized by Coomassie Brilliant blue staining as previously described [37]. Anti-purified-A-layer antiserum was obtained and assayed as previously described [38]. After SDS-PAGE, immunoblotting was carried out as previously described [39].

\section{Acknowledgments}

This work was supported by Plan Nacional de I + D + i grants (Ministerio de Economía y Competitividad, Spain), and Generalitat de Catalunya (Centre de Referència en Biotecnologia). We also thank Maite Polo for her technical assistance.

\section{Author Contributions}

S. Merino and J. M. Tomás conceived and designed the experiments; S. Merino, E. de Mendoza and R. Canals performed the experiments; all the authors analyzed the data; S. Merino and J. M. Tomás contributed reagents/materials/analysis tools and wrote the paper.

\section{Conflicts of Interest}

The authors declare no conflict of interest.

\section{References}

1. Austin, B.; Austin, D.A. Characteristics of the pathogens: Gram-negative bacteria. In Bacterial Fish Pathogens: Diseases of Farmed and Wild Fish; Austin, B., Austin, D.A., Eds.; Springer Praxis Publishing: Chichester, UK, 2007: pp. 81-150.

2. Scott, M. The pathogenicity of Aeromonas salmonicida (Griffin) in sea and brackish waters. J. Gen. Microbiol. 1968, 50, 321-327. 
3. Ishiguro, E.E.; Kay, W.W.; Ainsworth, T.; Chamberlain, J.B.; Buckley, J.T.; Trust, T.J. Loss of virulence during culture of Aeromonas salmonicida at high temperature. J. Bacteriol. 1981, 148, 393-400.

4. Belland, R.J.; Trust, T.J. Synthesis, export, and assembly of Aeromonas salmonicida A-layer analysed by transposon mutagenesis. J. Bacteriol. 1985, 163, 877-881.

5. Dooley, J.S.G.; Engelhardt, H.; Baumeister, W.; Kay, W.W.; Trust T.J. Three dimensional structure of an open form of the surface layer from the fish pathogen Aeromonas salmonicida. J. Bacteriol. 1989, 171, 190-197.

6. Phipps, B.M.; Kay, W.W. Immunoglobulin binding by the regular surface array of Aeromonas salmonicida. J. Biol. Chem. 1988, 263, 9298-9303.

7. Munn, C.B.; Ishiguro, E.E.; Kay, W.W.; Trust, T.J. Role of the surface components in serum resistance of virulent Aeromonas salmonicida. Infect. Immun. 1982, 36, 1069-1075.

8. Merino, S.; Albertí, S.; Tomás, J.M. Aeromonas salmonicida resistance to complement-mediated killing. Infect. Immun. 1994, 62, 5483-5490.

9. Aquilini, E.; Tomás, J.M, Lipopolysaccharides (Endotoxins). In Reference Module in Biomedical Sciences; Elsevier: Amsterdam, The Netherlands, 2015; in press.

10. Shaw, D.H.; Lee, Y.Z.; Squires, M.J.; Lüderitz, O. Structural studies on the O-antigen of Aeromonas salmonicida. Eur. J. Biochem. 1983, 131, 633-638.

11. Hart, M.J.; Lüderitz, O. Structure of the core oligosaccharide in the lipopolysaccharide isolated from Aeromonas salmonicida ssp. salmonicida. Carbohydr. Res. 1992, 231, 83-91.

12. Wang, Z.; Vinogradov, E.; Larocque, S.; Harrison, B.A.; Li, J.; Altman, E. Structural and serological characterization of the O-chain polysaccharide of Aeromonas salmonicida strains A449, 80204 and 80204-1. Carbohydr. Res. 2005, 340, 693-700.

13. Wang, Z.; Li, J.; Vinogradov, E.; Altman, E. Structural studies of the core region of Aeromonas salmonicida subsp. salmonicida lipopolysaccharide. Carbohydr. Res. 2006, 341, 109-117.

14. Westphal, O.; Jann, K. Bacterial lipopolysaccharide extraction with phenol-water and further application of the procedure. Methods Carbohydr. Chem. 1965, 5, 83-89.

15. Nogueras, M.M.; Merino, S.; Aguilar, A.; Benedí, V.J.; Tomás, J.M. Cloning, sequencing and role in serum susceptibility of porin II from mesophilic Aeromonas sp. Infect. Immun. 2000, 68, 1849-1854.

16. Jiménez, N.; Canals, R.; Saló, M.T.; Vilches, S.; Merino, S.; Tomás, J.M. The Aeromonas hydrophila $w b^{*} \mathrm{O} 34$ gene cluster: Genetics and temperature regulation. J. Bacteriol. 2008, 190, 4198-4209.

17. Artsimovitch, I.; Landick, R. The transcriptional regulator RfaH stimulates RNA chain synthesis after recruitment to elongation complexes by the exposed nontemplate DNA strand. Cell 2002, 109, 193-203.

18. Bailey, M.J.; Hughes, C.; Koronakis. V. RfaH and the ops element, components of a novel system controlling bacterial transcription elongation. Mol. Microbiol. 1997, 26, 845-851.

19. Ramos-Morales, F.; Prieto, A.I.; Beuzón, C.R.; Holden, D.W.; Casadesús, J. Role for Salmonella enterica Enterobacterial Common Antigen in Bile Resistance and Virulence. J. Bacteriol. 2003, 185, 5328-5332.

20. Klein, P.; Kanehisa, M.; DeLisi, C. The detection and classification of membrane-spanning proteins. Biochim. Biophys. Acta 1985, 815, 468-476. 
21. Izquierdo, L.; Merino, S.; Regué, M.; Rodríguez, F.; Tomás, J.M. A Klebsiella pneumoniae O-antigen heteropolysaccharide $(\mathrm{O} 12)$ requiring an ABC-2-trasnporter dependent pathway. J. Bacteriol. 2003, 185, 1634-1641.

22. Saigi, F.; Climent, N.; Piqué, N.; Sanchez, C.; Merino, S.; Rubirés, X.; Aguilar, A.; Tomás, J.M.; Regué, M. Genetic analysis of the Serratia marcescens N28b O4 antigen gene cluster. J. Bacteriol. 1999, 181, 1883-1891.

23. Knirel, Y.A.; Vinogradov, E.; Jimenez, N.; Merino, S.; Tomás, J.M. Structural studies on the R-type lipopolysaccharide of Aeromonas hydrophila. Carbohydr. Res. 2004, 339, 787-793.

24. Gudmundsdottir, B. K. Infections by atypical strains of the bacterium Aeromonas salmonicida. Iceland Agric. Sci. 1998, 12, 61-72.

25. Hanahan, D. Studies on transformation of Escherichia coli with plasmids. J. Mol. Biol. 1983, 166, 557-580.

26. Milton, D.L.; O'Toole, R.; Horstedt, P.; Wolf-Watz, H. Flagellin A is essential for the virulence of Vibrio anguillarum. J. Bacteriol. 1996, 178, 1310-1319.

27. Jiménez, N.; Lacasta, A.; Vilches, S.; Reyes, M.; Vazquez, J., Aquillini, E.; Merino, S.; Regué, M.; Tomás, J.M. Genetics and proteomics of Aeromonas salmonicida Lipopolysaccharide Core Biosynthesis. J. Bacteriol. 2009, 191, 2228-2236.

28. Austin, B.; Austin, D.A.; Dalsgaard, I.; Gudmundsdottir, B.K.; Høie, S.; Thornton, J.M.; Larsen, J.L.; O'Hici, B.; Powell, R. Characterization of atypical Aeromonas salmonicida by different methods. Syst. Appl. Microbiol. 1998, 21, 50-64.

29. Guzman, L.M.; Belin, D.; Carson, M.J.; Beckwith, J. Tight regulation, modulation, and high-level expression by vectors containing the arabinose $\mathrm{P}_{\mathrm{BAD}}$ promoter. J. Bacteriol. 1995, 177, 4121-4130.

30. Sambrook, J.; Fritsch, E.F.; Maniatis, T. Molecular Cloning: A Laboratory Manual, 2nd ed.; Cold Spring Harbor Laboratory: Cold Spring Harbor, NY, USA, 1989.

31. Sanger, F.; Nicklen, S.; Coulson, A.R. DNA sequencing with chain-terminating inhibitors. Proc. Natl. Acad. Sci. USA 1977, 74, 5463-5467.

32. Altschul, S.F.; Madden, T.L.; Schäffer, A.A.; Zhang, J.; Zhang, Z.; Miller, W.; Lipman, D.J. Gapped BLAST and PSI-BLAST: A new generation of protein database search programs. Nucleic Acids Res. 1997, 25, 3389-3402.

33. Thompson, J.D.; Higgins, D.G.; Gibson, T.J. CLUSTAL W: Improving the sensitivity of progressive multiple sequence alignment through sequence weighting, position specific gap penalties and weight matrix choice. Nucleic Acids Res. 1994, 22, 4673-4680.

34. Hitchcock, P.J.; Brown, T.M. Morphological heterogeneity among Salmonella lipopolysaccharide chemotypes in silver-stained polyacrylamide gels. J. Bacteriol. 1983, 154, 269-277.

35. Sawardeker, J.S.; Sloneker, J.H.; Jeanes, A. Spectrophotometric determination of high molecular weight quaternary ammonium cations in polysaccharides. Anal. Chem. 1965, 37, 243-246.

36. Widmalm, G.; Leontein, K. Structural studies of the Escherichia coli O127 O-antigen polysaccharide. Carbohydr. Res. 1993, 247, 87-89.

37. Esteve, C.; Amaro, C.; Toranzo, A.E. O-serogrouping and surface components of Aeromonas hydrophila and Aeromonas jandaei pathogenic for eels. FEMS Microbiol. Lett. 1994, 117, 85-90. 
38. Merino, S.; Aguilar, A.; Rubires, X.; Simón-Pujol, D.; Congregado, F.; Tomás, J.M. The role of the capsular polysaccharide of Aeromonas salmonicida in the adherence and invasion of fish cell lines. FEMS Microbiol. Lett. 1996, 142, 185-189.

39. Vilches, S.; Jiménez, N.; Merino, S.; Tomás, J.M. The Aeromonas dsbA mutation decreased their virulence by triggering type III secretion system but not flagella production. Microb. Pathog. 2012, $52,130-139$.

(C) 2015 by the authors; licensee MDPI, Basel, Switzerland. This article is an open access article distributed under the terms and conditions of the Creative Commons Attribution license (http://creativecommons.org/licenses/by/4.0/). 